\title{
Understanding the Molecular Relationship between Foot-and-Mouth Disease Virus Serotype $O$ of Indian Vaccine Strain with Strains across the World by Phylogenetic Analysis
}

\author{
Vishweshwar Kumar Ganji ${ }^{1 *}$, Sampath Kontham ${ }^{2}$ and Mallesh Pottabathula ${ }^{3}$
}

${ }^{1}$ FMD Research Lab, Indian Veterinary Research Institute, Bengaluru, Karnataka-560024, India

${ }^{2}$ Department of Animal Genetics and Breeding, ${ }^{3}$ Department of Veterinary Parasitology, C.V.Sc, PVNR Telangana Veterinary University, Hyderabad, Telangana-500030, India

*Corresponding author

\section{A B S T R A C T}

\section{Keywords}

FMD, Virus, Phylogeny, Epidemiology, Molecular characterization

Article Info

Accepted: 04 April 2018 Available Online: 10 May 2018
Foot-and-mouth disease is one of the important animal virus known to be highly infectious and causing a serious trade barrier. For effective control of FMD there is a need for in depth understanding of the virus epidemiology. The present study has been undertaken to understand the molecular relationship between the strains across world in comparison to Indian vaccine strain and virus isolate of 2010. The study is done by comparing the nucleotide sequence of VP1 protein, known to induce neutralizing antibodies by phylogenetic analysis. Based on phylogenetic analysis we found that the disease in India is mainly caused by transboundary evolution of virus but not due to the vaccine strain.

\section{Introduction}

Foot-and mouth-disease is an infectious and highly contagious viral disease of domestic and wild cloven hoofed animals causing a huge economic loss in agriculture worldwide (Kandeil et al., 2013). As per the latest ICTV virus taxonomy release the etiological agent, FMD virus (FMDV) is grouped under the genus Apthovirus of family Picornaviridae
(ICTV, 2015). FMD was first recognised by a Francisian monk Hieronymus Fracastorius (1546) in cattle, and Loeffler and Frosch (1897) demonstrated for the first time a filterable agent causing animal disease, FMD. FMD virus exists as seven different serologically distinct types namely, serotypes O, A (Valle and Carre, 1922), C (Waldmann and Trautwein, 1926), SAT 1, SAT2, SAT3 (Brooksby, 1958), Asial (Brooksby and 
Roger, 1957) with no cross immune protection (Kitching, 1998). The disease plays an important role in global trade and is a priority disease among the list A diseases published by Office International des Epizootics (OIE).The disease is endemic in large areas of Africa, Asia, and South America and has the potency to cross international boundaries to create epidemics in non-infected areas (Knowles et al., 2001; Alexandersen et al., 2003). The 2001/2002 European outbreak explains the huge economic loss (6000 million Euros) caused by FMD (Domingo et al., 2003). In India, FMD Serotype O is responsible for $80 \%$ of outbreaks confirmed (2150 outbreaks) whereas $12 \%$ accounts for Asia 1 and $8 \%$ by serotype A (Subramaniam et al., 2013). The VP1 protein comprises of 213 amino acid residues (Acharya et al., 1989) is concerned in formation of neutralizing antibodies and attachment to susceptible cells (Wild et al., 1969). VP1 is the most studied FMDV protein due to its significance for virus attachment, entry, protective immunity and serotype specificity (Jackson et al., 2003). The molecular characterization and understanding the epidemiology of the virus can give details into the control of FMD. Hence, in present study, we have retrieved the VP1 sequences from NCBI and phylogenetically analyzed the molecular relation of FMDV Indian vaccine strain against the FMDV strains across the world.

\section{Materials and Methods}

\section{Retrieval of sequence data from NCBI}

We searched GenBank for complete sequences of the FMDV VP1protein-coding gene of serotype $\mathrm{O}$ and recorded the geographic location and date of isolation. A total of 21 sequences of FMDV strains across the world including Indian vaccine strain were retrieved from the nucleotide database of NCBI.

\section{Multiple sequence alignment}

The sequences of 20 strains were aligned against the Indian vaccine strain and the amino acid sequence is compared for variable regions.

\section{Phylogenetic analysis}

The evolutionary distance matrix was constructed by calculating pairwise distance of the aligned sequences using MEGA 6. Further, the time tree and phylogenetic tree were constructed by neighbour joining statistical method in MEGA 6.

The bootstrap replications used are 500; model used is Tamura3-parameter model.

\section{Results and Discussion}

By aligning the amino acid sequences of different FMDV strains (20) in comparison to Indian vaccine strain we found the later has three changes incorporated in it. From Figure 1 the changes of threonine to phenylalanine at position 4 (T4P), phenylalanine to serine at position $140(\mathrm{P} 140 \mathrm{~S})$, serine to asparagine at position 197 (S197N) can be observed. Figure 2 shows the evolutionary divergence between the sequences of FMDV Indian vaccine strain and Indian isolate 2010 as 0.113, FMDV Indian vaccine strain and FMDV O Manisa as 0.096. From the results presented in Figure 3 the FMDV Indian vaccine strain showed closest relatedness with the KRG isolate of 2006 with $80 \%$ sequence identity, FMDV Indian isolate 2010 showed closest relatedness with the BAN and NEP isolate of 2009 with $100 \%$ sequence identity, FMDV O Manisa showed closest relatedness with the IRN isolate of 2007 with $100 \%$ sequence identity. From the results presented in Figure 4 the FMDV Indian vaccine strain showed lowest divergence with the KRG isolate of 2006 with 0.01 divergence time, FMDV Indian isolate 
2010 showed lowest divergence with the BAN and NEP isolate of 2009 with 0.00 divergence time, FMDV O Manisa showed lowest divergence with the IRN isolate of 2007 with 0.01 divergence time but shown $>0.2$ divergence time with others.

Fig.1 Amino acid sequence alignment showing the differences in FMDV Indian vaccine strain in comparison with other 20 strains generated by multiple sequence alignment by Clustal $\omega$
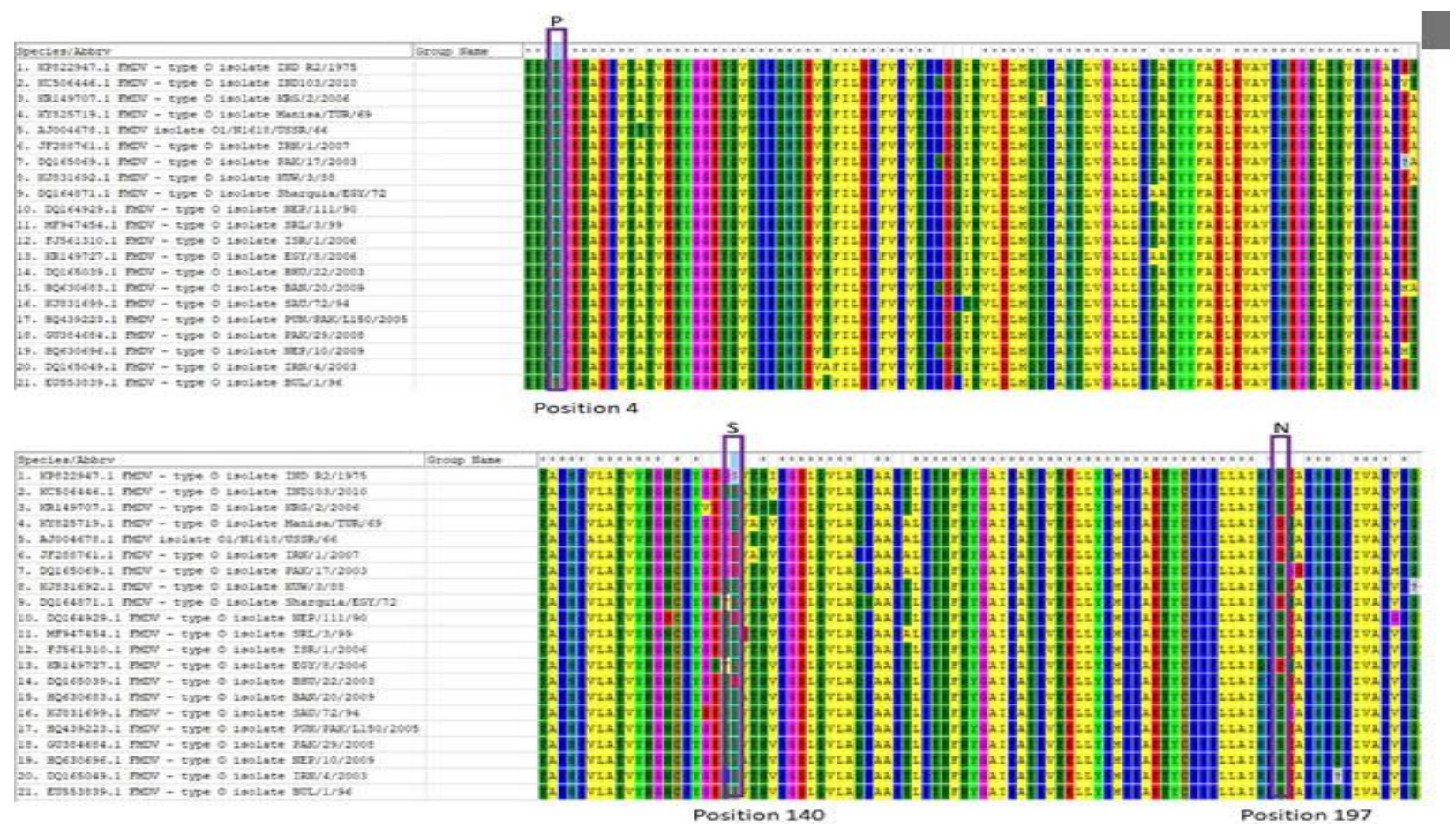

Fig.2 Estimates of evolutionary divergence between sequences. The number of base substitutions per site from between sequences is shown. Analyses were conducted using the Tamura 3parameter model (Tamura, 1992). The rate variation among sites was modelled with a gamma distribution. The analysis involved 21 nucleotide sequences. Evolutionary analyses were conducted in MEGA6 (Tamura et al., 2013)

\begin{tabular}{|c|}
\hline 1. KP822947.1 FMDV - type 0 isolate IND R2/1975 \\
\hline 2. KC506446.1 FMDV - type 0 isolate IND103/2010 \\
\hline 3. KR 149707.1 FMDV - type O isolate KRG/2/2006 \\
\hline 4. KY825719.1FMDV - type 0 isolate Manisa/TUR/69 \\
\hline 5. AJ004678.1 FMDV isolate 01/N1618/USSR/66 \\
\hline 6. JF288761.1 FMDV - type 0 isolate IRN/1/2007 \\
\hline 7. DQ165069.1FMDV - type 0 isolate PAK/17/2003 \\
\hline 8. KJ831692.1 FMDV - type O isolate KUW/3/88 \\
\hline 9. DQ164871.1 FMDV - type 0 isolate Sharquia/EGY/72 \\
\hline 10. DQ164929.1 FMDV - type 0 isolate NEP/111/90 \\
\hline 11. MF947454.1FMDV - type O isolate SRL/3/99 \\
\hline 12. FJ561310,1 FMDV - type 0 isolate ISR/1/2006 \\
\hline 13. KR149727.1FMDV - type 0 isolate EGY/8/2006 \\
\hline 14. DQ 165039.1 FMDV - type 0 isolate BHU/22/2003 \\
\hline 15. HQ630683.1 FMDV - type O isolate BAN/20/2009 \\
\hline 16. KJ831699.1 FMDV - type O isolate SAU/72/94 \\
\hline 17. HQ439223.1 FMDV - type 0 isolate PUN/PAK/150/200 \\
\hline 18. GU384684.1 FMDV - type 0 isolate PAK/29/2008 \\
\hline 19. HQ630696.1 FMDV - type O isolate NEP/10/2009 \\
\hline 20. DQ165049.1FMDV - type 0 isolate IRN/4/2003 \\
\hline 21. EU553839.1FMDV - type 0 isolate BUL/1/96 \\
\hline
\end{tabular}

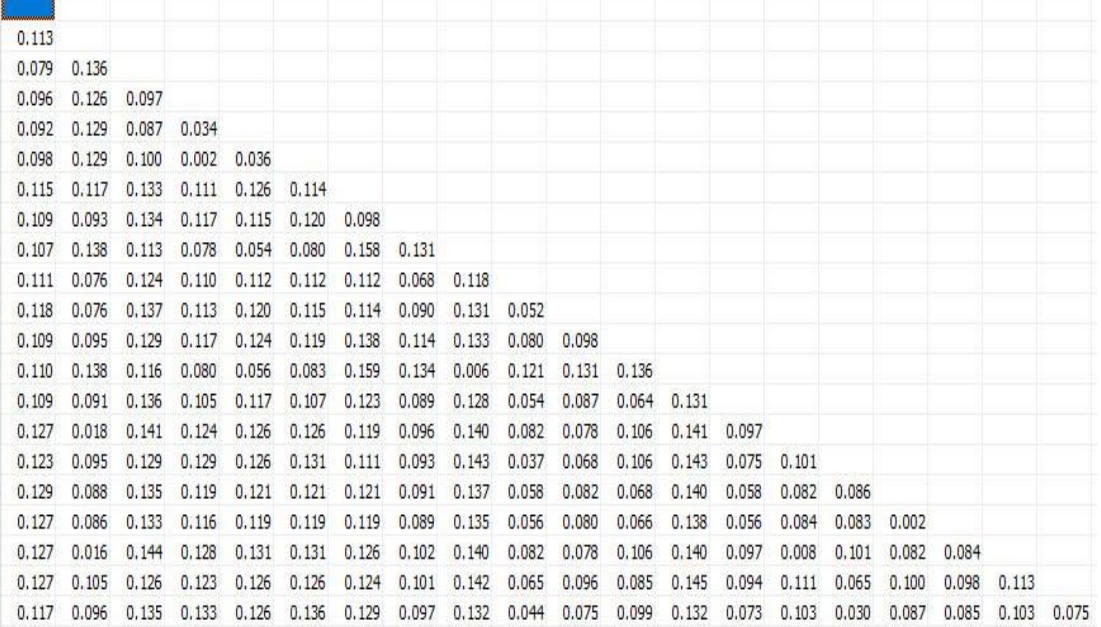


Fig.3 Evolutionary relationships of 21 strains of FMDV serotype O. The evolutionary history was inferred using the Neighbor-Joining method (Saitou and Nei, 1987). The evolutionary distances were computed using the Tamura 3-parameter method (Tamura, 1992) and are in the units of the number of base substitutions per site. The rate variation among sites was modeled with a gamma distribution. The analysis involved 21 nucleotide sequences. Evolutionary analyses were conducted in MEGA6 (Tamura et al., 2013)

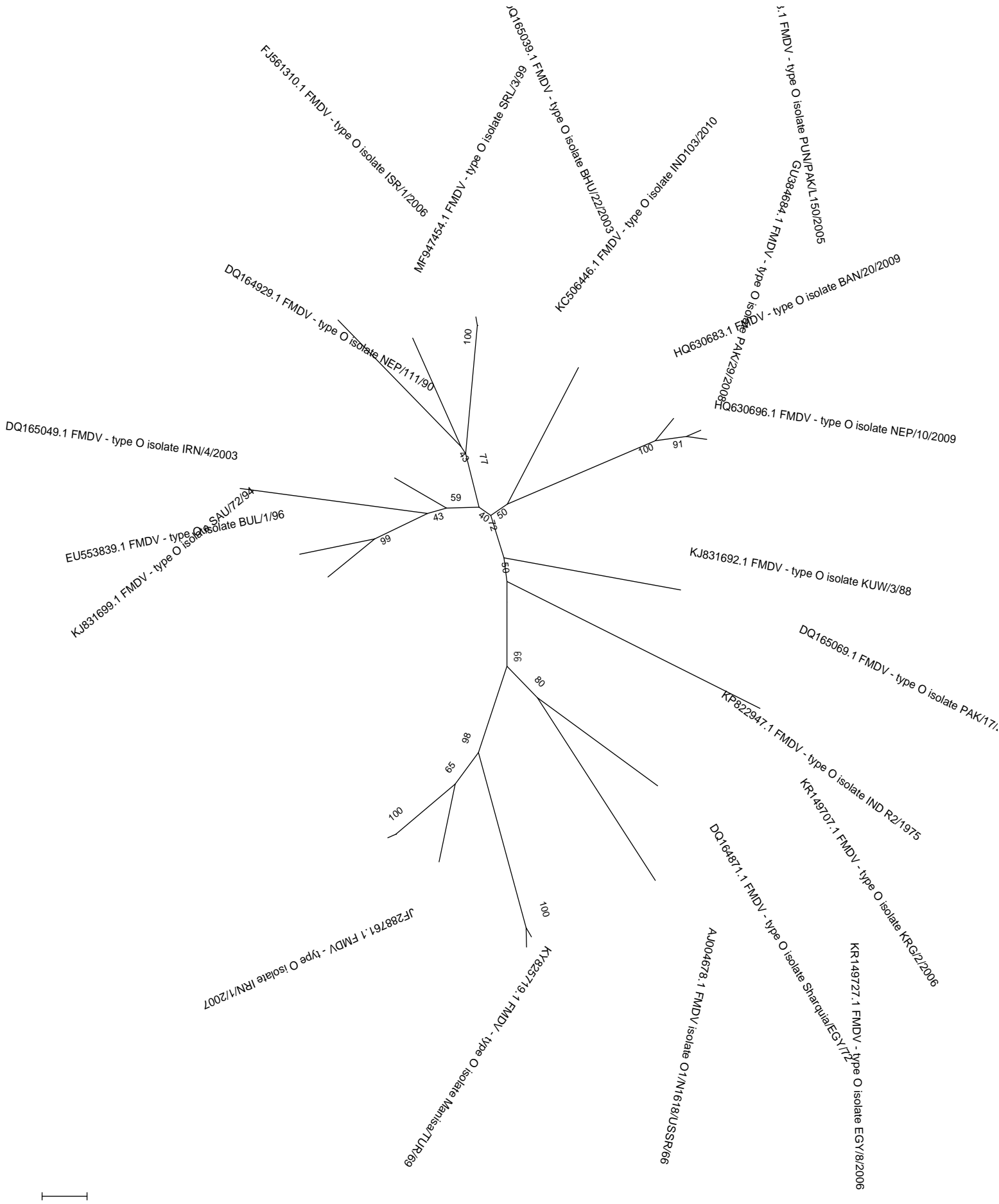


Fig.4 Evolutionary relationships of 21 strains of FMDV serotype O (timetree). The evolutionary history was inferred using the Neighbor-Joining method (Saitou and Nei, 1987). Divergence times for all branching points in the topology were calculated with the RelTime method (Tamura et al., 2012) using the branch lengths contained in the inferred tree. The analysis involved 21 nucleotide sequences. Evolutionary analyses were conducted in MEGA6 (Tamura et al., 2013)

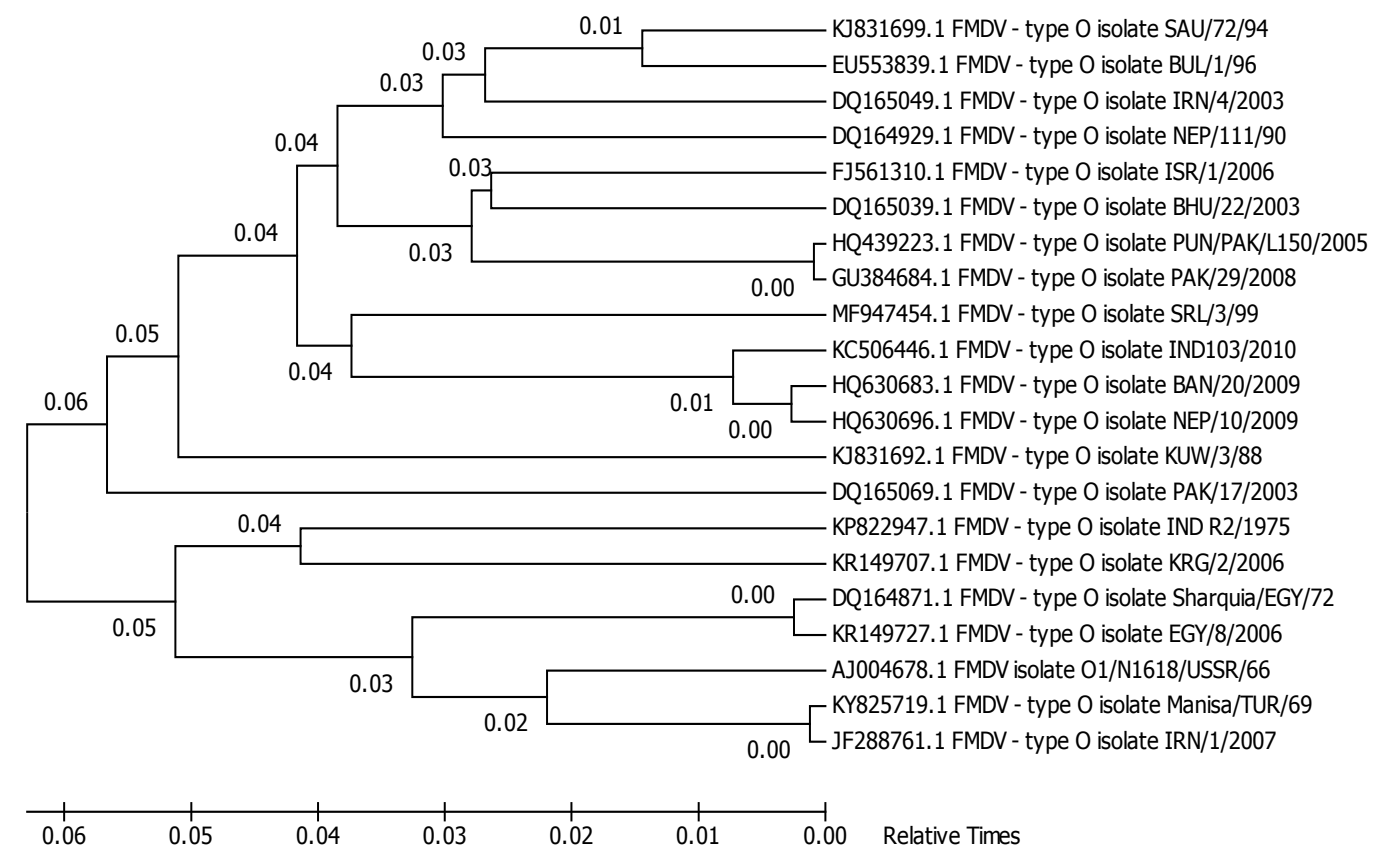

Foot-and-mouth disease virus is one of the most contagious viral pathogen that cause huge risk for the livestock economy with almost having a host range of among 70 species of cloven-hoofed mammals (Carrillo et al., 2005). In India, FMD Serotype $\mathrm{O}$ is responsible most of the FMD out breaks (Subramaniam et al., 2013), the serotype we used in the study. The VP1 protein on which the present study was performed comprises of 213 amino acid residues (Acharya et al., 1989) with major antigenic sites of virus capsid located between amino acids 138 and 160 (Strohmaier et al., 1982) was concerned in formation of neutralizing antibodies and attachment to susceptible cells (Wild et al., 1969). Hence, in this study the phylogenetic analysis was conducted on VP1 protein to observe the genetic relatedness of FMDV Indian vaccine strain. The VP1 based sequence similarity tree shown FMDV Indian vaccine strain closely related with the KRG isolate of 2006, FMDV Indian isolate 2010 closely related with the BAN and NEP isolate of 2009, FMDV O Manisa closely related with the IRN isolate of 2007. The genome of FMDV is known to have a high mutation rate of about 1-8 nucleotides per replication cycle (Domingo et al., 1995). In the present study, also we observed many nucleotide changes between 21 strains. Further, the comparison of amino acid sequence of 21 FMDV strains revealed three major amino acid changes in Indian vaccine strain, at position 4, 140, 197. The virus isolate from India during 2010 show large divergence from the vaccine strain as evident from the phylogenetic tree. For phylogenetic interpretations the FMDV that differ in $2-5 \%$ from each other are generally believed to originate from same enzootic (Samuel et al., 1997). However, we found much more difference between vaccine strain 
and 2010 isolate, which indicate that the virus isolate of 2010 from infected animals are not related to vaccine strain. This may hint that the cause for outbreak may be due to the entry of new virus strain transboundary.

The present study describes the requirement for implementation of strict control measures to stop the emergence of virus transboundary. Further, the study also hints the requirement of more advanced alternative vaccines that can protect against different strains of virus.

\section{Acknowledgment}

We would like to acknowledge IVRI, Izatnagar for providing resources that are required for the study.

\section{References}

Acharya, R., Fry, E., Stuart, D., Fox, G., Rowlands, D. and Brown, F. 1989. The three-dimensional structure of foot-andmouth disease virus at $2.9 \AA$ resolution: 709-716.

Alexandersen, S., Zhang, Z., Donaldson, A.I. and Garland, A.J.M. 2003. The pathogenesis and diagnosis of foot-andmouth disease. Journal of comparative pathology, 129(1): 1-36.

Brooksby, J. 1958. The virus of foot-andmouth disease. Advances in virus research, 5: 1-37.

Brooksby, J.B. and Rogers, J. 1957. Methods used in typing the virus of foot-andmouth disease at Pirbright, 1950 55. Methods of typing and cultivation of foot-and-mouth disease virus, European Productivity Agency of the Organisation for European Economic Co-operation, Project, 31: 34.

Carrillo, C., Tulman, E.R., Delhon, G., Lu, Z., Carreno, A., Vagnozzi, A., Kutish, G.F. and Rock, D.L. 2005. Comparative genomics of foot-and-mouth disease virus. Journal of virology, 79(10): 64876504.

Domingo, E., Escarmís, C., Baranowski, E. Ruiz-Jarabo, C.M., Carrillo, E., Núñez, J.I. and Sobrino, F. 2003. Evolution of foot-and-mouth disease virus. Virus research, 91(1): 47-63.

Domingo, E., Mateu, M.G., Escarmis, C., Martinez-Salas, E., Andreu, D., Giralt, E., Verdaguer, N. and Fita, I., 1995. Molecular evolution of aphthoviruses. Virus Genes, 11(2-3): 197-207.

Fracastorius, H. 1546. De sympathia et antipathia rerum liber unus. De contagione et contagiosis morbis et eorum curatione liber I, Venice, Heirs of LA Junta.

ICTV, 2015. Virus taxonomy: 2015 release http://www.ictvonline.org/virusTaxono my.asp

Jackson, T., King, A.M., Stuart, D.I. and Fry, E. 2003. Structure and receptor binding. Virus research, 91(1): 33-46.

Kandeil, A., El-Shesheny, R., Kayali, G., Moatasim, Y., Bagato, O., Darwish, M., Gaffar, A., Younes, A., Farag, T., Kutkat, M.A. and Ali, M.A. 2013. Characterization of the recent outbreak of foot-and-mouth disease virus serotype SAT2 in Egypt. Archives of virology, 158(3): 619-627.

Kitching, R.P. 1998. A recent history of footand-mouth disease. Journal of Comparative Pathology, 118(2): 89108.

Knowles, N.J., Samuel, A.R., Davies, P.R., Kitching, R.P. and Donaldson, A.I. 2001. Outbreak of foot-and-mouth disease virus serotype $\mathrm{O}$ in the UK caused by a pandemic strain. The Veterinary Record, 148(9): 258.

Loeffler, F. and Frosch, P. 1897. Summarischer Bericht über die Ergebnisse der Untersuchungen der Kommission zur Erforschung der Maul- 
und Klauenseuche bei dem Institut für Infektionskrankheiten in Berlin. Dt Med Wschr, 98: 80-84.

Saitou N. and Nei M. (1987). The neighborjoining method: A new method for reconstructing phylogenetic trees. Molecular Biology and Evolution, 4:406-425.

Samuel, A.R., Knowles, N.J., Kitching, R.P. and Hafez, S.M., 1997. Molecular analysis of foot-and-mouth disease type $O$ viruses isolated in Saudi Arabia between 1983 and 1995. Epidemiology \& Infection, 119(3): 381-389.

Strohmaier, K., Franze, R.T. and Adam, K.H. 1982. Location and characterization of the antigenic portion of the FMDV immunizing protein. Journal of General Virology, 59(2): 295-306.

Subramaniam, S., Pattnaik, B., Sanyal, A., Mohapatra, J.K., Pawar, S.S., Sharma, G.K., Das, B. and Dash, B.B. 2013. Status of Foot- and- mouth Disease in India. Transboundary and emerging diseases, 60(3): 197-203.

Tamura K. (1992). Estimation of the number of nucleotide substitutions when there are strong transition-transversion and $\mathrm{G}$ + C-content biases. Molecular Biology and Evolution, 9:678-687.

Tamura K., Battistuzzi FU, Billing-Ross P, Murillo O, Filipski A, and Kumar S. (2012). Estimating Divergence Times in Large Molecular Phylogenies. Proceedings of the National Academy Sciences, 109:19333-19338.

Tamura K., Stecher G., Peterson D., Filipski A., and Kumar S. (2013). MEGA6: Molecular Evolutionary Genetics Analysis version 6.0. Molecular Biology and Evolution, 30: 2725-2729.

Valle'e, H., Carre'H. (1922). A pluralite du virus aphteux CR Hebd. Acad. Sci. Paris, 174, 1498-1500.

Waldmann, O. and Trautwein, K. 1926. Experimentelle Untersuchungen über die Pluralität des Maul-und Klauenseuchevirus. Berl. Tierärztl. Wschr, 42(35): 569-571.

Wild, T.F., Burroughs, J.N. and Brown, F. 1969. Surface structure of foot-andmouth disease virus. Journal of General Virology, 4(3): 313-320.

\section{How to cite this article:}

Vishweshwar Kumar Ganji, Sampath Kontham and Mallesh Pottabathula. 2018. Understanding the Molecular Relationship between Foot-and-Mouth Disease Virus Serotype O of Indian Vaccine Strain with Strains across the World by Phylogenetic Analysis. Int.J.Curr.Microbiol.App.Sci. 7(05): 99-105. doi: https://doi.org/10.20546/ijcmas.2018.705.013 